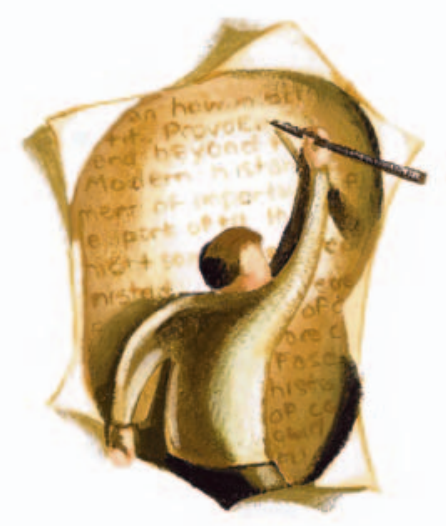

\section{Lactate and the osmolar gap}

Although the teaching case report in the March 27 issue on a negative anion gap and elevated osmolar gap resulting from lithium overdose ${ }^{1}$ is interesting, I identified the following concern.

In the third paragraph from the end of the report, the authors listed lactate as one of the potential causes of an elevated osmolar gap that they excluded. It is unfortunate that they perpetuated this common misperception of the role of lactate. An elevated lactate concentration does not account for an elevated osmolar gap because the lactate is accounted for in the osmolality calculation by multiplying the sodium concentration by 2 .

\section{Frances M. Rosenberg MD PhD} Pathology and Laboratory Medicine St. Paul's Hospital

Vancouver, BC

Competing interests: None declared.

\section{REFERENCE}

I. Sood MM, Richardson R. Negative anion gap and elevated osmolar gap due to lithium overdose. CMAJ 2007;176(7):92I-3.

DOI:I0.I503/cmaj.I07006I

\section{[The authors respond:]}

We thank Frances Rosenberg for her comment on our paper. ${ }^{1}$ The contribution of lactic acid to the osmolar gap is complex. Lactic acid ionizes; Rosenberg astutely mentions that the cation accompanying lactate is sodium. Theo- retically, therefore, an elevated lactate concentration should not elevate the osmolar gap because the osmolar gap calculation accounts for sodium. However, elevations in the osmolar gap with lactic acidosis and shock have been consistently reported in both human and animal studies. ${ }^{2-4}$

There are 3 likely explanations for these observations. First, many reports have described elevations in the osmolar gap in patients who have prolonged stays in the intensive care unit with sepsis or organ hypoperfusion. Medications such as lorazepam, multivitamin preparations and nitroglycerin are often stored in propylene glycol, a solvent that is known to increase the osmolar gap and lead to lactic acidosis. ${ }^{5}$ Second, in alcoholic patients without detectable serum ethanol levels, endogenous compounds such as glycerol, acetone and acetone's metabolic by-products have been shown to elevate the osmolar gap. ${ }^{6}$ If these patients have concurrent liver damage, a type 2 lactic acidosis may be present because the liver fails to clear lactate. These 2 examples illustrate situations in which an elevated osmolar gap and elevated lactate concentration may be detected concurrently; this may explain the confusion in the literature.

Lastly, in experimental settings, Schelling and colleagues found that the osmolar gap in a cohort of hospitalized patients with lactic acidosis was elevated (Io. $3 \pm 2.0 \mathrm{mmol} / \mathrm{kg}$ ) compared with that of control patients. ${ }^{2}$ It is felt that with lactic acidosis, cell breakdown leads to the release of other products of glycogen breakdown that contribute to the elevation of the osmolar gap. This contribution is relatively minor (generally leading to an osmolar gap of less than $25 \mathrm{mOsmol} / \mathrm{kg}$ ), but it is detectable. Thus, we feel that an elevated lactate concentration does make a contribution to increasing the osmolar gap.

\section{Manish M. Sood MD \\ Robert Richardson MD \\ Department of Medicine \\ Division of Nephrology \\ Toronto General Hospital \\ Toronto, Ont.}

Competing interests: None declared.

\section{REFERENCES}

I. Sood MM, Richardson R. Negative anion gap and elevated osmolar gap due to lithium overdose. CMAJ 2007;176(7):92I-3

2. Schelling JR, Howard RL, Winter SD, et al. Increased osmolar gap in alcoholic ketoacidosis and lactic acidosis. Ann Intern Med I990;I13:580.

3. DiNubile MJ. Serum osmolality. $N$ Engl J Med I984;310:1609.

4. Linden C, Lovejoy, F. Illnesses due to poisons, drug overdosage and envenomation. In: Harrison's principles of internal medicine. I4th ed. New York: McGraw-Hill; I998. p. 2523-5.

5. Chicella M, Jansen P, Parthiban A, et al. Propylene glycol accumulation associated with continuous infusion of lorazepam in pediatric intensive care patients. Crit Care Med 2002;30:2752-7.

6. Braden GL, Strayhorn C, Germain M, et al. Increased osmolal gap in alcoholic acidosis. Arch Intern Med I993;153:2377-80.

DOI:I0.1503/cmaj.1070073

\section{Corrections}

In the July 17 issue of $C M A J$, a map accompanying a news story should have identified Afghanistan's eastern and southern neighbour as Pakistan.

\section{REFERENCE}

I. Kondro W. Afghanistan: Outside the comfort zone in a war zone. $C M A J$ 2007;177[2]:13I-4.

DOI:I0.1503/cmaj.07107I

In the Review article ${ }^{1}$ in the May 22 issue of $C M A J$, there was an error in Table I. A hemorrhagic effusion should have a negative Gram's staining result and negative bacteria culture, and not positive as indicated.

\section{REFERENCE}

I. Kherani RB, Shojania K. Septic arthritis in patients with pre-existing inflammatory arthritis. CMAJ 2007;176(II):1605-8.

DOI:I0.1503/cmaj.071069

In a recent article ${ }^{1}$ the prevalence estimates for HIV and hepatitis C (HCV) in Canada have been reversed. They should read $0.18 \%$ for $\mathrm{HIV}$ and $0.8 \%$ for $\mathrm{HCV}$.

\section{REFERENCE}

I. Calzavara L, Ramuscak N, Burchell AN, et al. Prevalence of HIV and hepatitis C virus infections among inmates of Ontario remand facilities. CMAJ 2007;177(3):257-6I.

DOI:I0.1503/cmaj.071082 